\title{
INTERACTION EFFECT OF LEADER-MEMBER EXCHANGE AND STRESS MINDSET ON CHALLENGE STRESSOR AND JOB PERFORMANCE RELATIONSHIP
}

\author{
DOI: 10.17261/Pressacademia.2019.1158 \\ RJBM- V.6-ISS.4-2019(5)-p.281-290 \\ Hsiao-Ling Chen ${ }^{1}$, Shih-Chieh Fang ${ }^{2}$ \\ ${ }^{1}$ National Cheng Kung University, Department of Business Administration, No.1, University Road, Tainan City 701, Taiwan (R.O.C) \\ hsiaoochen@gmail.com, ORCID: 0000-0002-2459-127 \\ ${ }^{2}$ National Cheng Kung University, Department of Business Administration, No.1, University Road, Tainan City 701, Taiwan (R.O.C) \\ fangsc@mail.ncku.edu.tw, ORCID: 0000-0001-5006-8677
}

Date Received: November 4, 2019

Date Accepted: December 18, 2019

To cite this document

Chen, H.-L., Fang, S.-C. (2019). Interaction effect of leader-member exchange and stress mindset on challenge stressor and job performance relationship. Research Journal of Business and Management (RJBM), V.6(4), p.281-290.

Permemant link to this document: http://doi.org/10.17261/Pressacademia.2019.1158

Copyright: Published by PressAcademia and limited licenced re-use rights only.

\section{ABSTRACT}

Purpose - This study integrated job demands-resources model and concept of stress mindset to examine a three-way interaction model. Testing the effect of challenge stressor, leader-member exchange and positive stress mindset on job performance.

Methodology - Research data were collected from four hundred eighty-seven employees during different business in Taiwan. Hierarchical regression analysis was conducted, and results supported the three-way moderation effect.

Findings- The findings suggested that when supervisors' social support resources were strong, positive stress mindset can better improve employee's job performance.

Conclusion- There is a three-way interaction moderation effect of challenge stressors, leader-member exchange and positive stress mindset on job performance. A contribution of the present study to research is that we linked job demands-resources model and stress mindset theory to explain a boundary condition effect in stress issue.

Keywords: Leader-member exchange, stress mindset, three-way interaction JEL Codes: D23

\section{INTRODUCTION}

Job stress has always been an important issue for academics and practitioners, because may affect employee attitudes and physical and mental health (Bliese, Edwards, \& Sonnentag, 2017; Cooper, Dewe, \& O'Driscoll, 2001; Ganster \& Rosen, 2013). Early studies have argued that stress is harmful and negatively affects organizations and individuals, thus people must adopt effective strategies to prevent or reduce stress incidence (Atkinson, 2004; Bodenmann, Meuwly, Bradbury, Gmelch, \& Ledermann, 2010; McEwen \& Seeman, 1999; Schwabe \& Wolf, 2010). In fact, there are two types of stressors (Cavanaugh, Boswell, Roehling, \& Boudreau, 2000), which most scholars agreed that hindrance stressors will lead to negative outcomes, and challenge stressors lead to positive outcomes (Abbas \& Raja, 2019; Cavanaugh et al., 2000; LePine, Podsakoff, \& LePine, 2005; Podsakoff, LePine, \& LePine, 2007; Webster, Beehr, \& Christiansen, 2010).

Based on job demands-resources (JDR) model, Bakker and Demerouti (2007) proposed that job stress exists in any occupation, and it can be broadly divided into job demands and job resources, and the interaction effect between job demands and job resources can reduce strain or enhance job motivation. Some prior studies on conservation of resources (COR) theory have identified the supplemental resources of supervisors to alleviate employee work stress and lessen negative consequences (Campbell, Perry, Maertz Jr, Allen, \& Griffeth, 2013; Thomas \& Lankau, 2009). Theoretically, based on JDR model and COR theory, job resources should reduce negative outcomes, but this study suggest that individual's perception of stressors have an additional 
effect beside job resources. In fact, the nature of work stress might different, and perception of experienced stress during the process of pursuit working goals may differ among people(González-Morales \& Neves, 2015).

Overall, we propose that the nature of the stressors and the perceptions of stressors will affect employee subsequent behaviors. We introduce the concept of stress mindset, which refers to the extent to which one believes that stress enhances or debilitates (Crum, Salovey, \& Achor, 2013). Specifically, our study focuses on challenge stressors (job demands), leader-member exchange (job resources), and positive stress mindset (perception) will have a three-way moderation effect on job performance. First, we expect this paper contribute to integrate the JDR model and leadership theory to explain the role of job resources and personal characteristic in the relationship between job demands and job performance. Second, we extend the Crum et al. (2013) stress mindset concept to examine its moderating role beyond leader-member exchange in work behaviors. Finally, we highlight the possible three-way moderating role of stress mindset in the job demands-resources model.

\section{LITERATURE REVIEW}

Cavanaugh et al. (2000) followed transactional theory of stress (Lazarus \& Folkman, 1984), classified job stressors into challenge stressors and hindrance stressors. Hindrance stressors were defined as "work-related demands or circumstances that tend to constrain or interfere with an individual's work achievement and that do not tend to be associated with potential gains for the individual," for instance, role ambiguity, role conflict, hassle, red tape, organizational politics, and job insecurity (Cavanaugh et al., 2000, p. 68). On the other hand, challenge stressors were defined as "work-related demands or circumstances that, although potentially stressful, have associated potential gains for individuals", such as workload, time pressure, job responsibility, and job complexity (Cavanaugh et al., 2000, p. 68).

\subsection{Job Demands-Resources Model}

The JDR model was proposed by Demerouti, Bakker, Nachreiner, and Schaufeli (2001), they divided the risk factors of job stress exists in any occupation into two categories: job demands and job resources. Both job demands and job resources involve the physical, psychological, social, and organizational aspects of the job. "Job demands" require that people continue to invest physical and psychological efforts or skills toward work and incur individual's physical and mental depletion (Bakker \& Demerouti, 2007), such as workload (Bakker, Demerouti, de Boer, \& Schaufeli, 2003), customer aggression (Grandey, Dickter, \& Sin, 2004) and organizational change (Rafferty \& Griffin, 2006). "Job resources" not only help to achieve goals and reduce the work requirements and physical and mental consumption related to work but also stimulate individual growth and development (Bakker \& Demerouti, 2007), such as higher salaries, supervisor or colleague support (Karatepe, Yavas, \& Babakus, 2007) and high performance work system (Fu, 2013). The JDR model (Bakker \& Demerouti, 2007, 2017) contains two mechanisms, one is job demands deplete an employee's physical and psychological resources, bring strain, jeopardize the employee's health, and result in poor job performance; the other is job resources help in achieving work goals; therefore, the employee's internal motivation is activated, resulting in a good job performance. Besides, job demands and job resources exist interaction effect, such job resources can alleviate the relationship between job demands and strain, whereas job demands can strengthen the relationship between job resources and motivation.

Based on JDR model (Bakker \& Demerouti, 2007, 2017; Demerouti et al., 2001) and dyadic viewpoint of stressor (Cavanaugh et al., 2000), hindrance stressor belongs to "bad" job demands and it will obstruct job performance, but challenge stressor belongs to "good" job demand, should be more able to activate job resources and promote job performance and the relationship between job resources and work motivation more relevant (Bakker \& Demerouti, 2017; Bakker, Demerouti, \& Sanz-Vergel, 2014). Based on our knowledge, challenge stressors are positively related to job satisfaction, motivation, work engagement, loyalty and performance (Abbas \& Raja, 2019; LePine et al., 2005; Lin, Ma, Wang, \& Wang, 2015; Podsakoff et al., 2007; Wallace, Edwards, Arnold, Frazier, \& Finch, 2009; Webster et al., 2010).Therefore, we propose hypothesis 1 as follow:

Hypothesis 1: Challenge stressors have positive effect on job performance.

\subsection{Leader-Member Exchange}

Leader-member exchange (LMX) theory focuses on the dyadic relationship between leaders and followers, it is the employees' perceptions of the quality of the interpersonal social exchange between them and their immediate supervisor (Graen, 1976; Liden \& Maslyn, 1998). The core notion of LMX is that leaders treat their subordinates differently depending on the quality of the social exchange between them (Graen \& Uhl-Bien, 1995; Liden, Sparrowe, \& Wayne, 1997). Due to limited resources of the organization and the limited time and ability of supervisors, leaders were unlikely to form a close relationship with all subordinates (Graen \& Scandura, 1987), leaders will selectively allocate these resources and form the quality of exchange relations between leaders and 
subordinates, thus developed close relations (in-group) and weak relationships (out-group). Low-quality of LMX relationships are regarded as those that entail a unidirectional top-down influence, economic exchange behaviors, and formal role-defined associations. The characteristics of high-quality LMX relationships are the obligation to trust and respect each other (Graen \& UhlBien, 1995). Leaders rely more heavily on followers, interact with employees more frequently, and encourage them to undertake more responsibilities in such relationships. Followers assume additional duties and perform beyond their contractual expectations (Dunegan, Duchon, \& Uhl-Bien, 1992), and leaders provide subordinates with social support, which is characterized as being empathetic and supportive of subordinates' needs (Kurtessis et al., 2017; Medler-Liraz, 2014).

\subsection{Three-Way Interaction Hypothesis Development}

Dweck (2008) defined mindset as a mental frame or lens through which we selectively organize and encode information and guide an individual's corresponding actions and responses through a unique method of understanding. Crum et al. (2013) proposed that stress mindset is the extent to which an individual believes that stress enhances or debilitates, suggested that changing one's stress mindset improves a person's response to stress. Specifically, if an individual's mindset is stress-is-enhancing (positive stress mindset), they will utilize stress to achieve their goals, which engenders positive consequences. By contrast, if an individual's mindset is stress-is-debilitating (negative stress mindset), that they will avoid or manage the stress to prevent negative or debilitating outcomes.

When employees encounter challenge stressors, employees are convinced that the job demands provide opportunities for growth and learning. At this time, we proposed that leaders will respect and trust their subordinate can overcome the problem in highquality LMX situation, and also provide some advice and social support for subordinate (Kurtessis et al., 2017; Medler-Liraz, 2014; Wayne, Shore, \& Liden, 1997). In addition to leader may plays supportive role, subordinates will assume additional duties and perform beyond their contractual expectations by invest more effort to complete the challenging task (Dunegan et al., 1992), it will trigger employees to hold a positive stress mindset (Crum et al., 2013), keep positive confident and utilizing their capacity and professional knowledge to help leaders achieve organizational goal and enhance their job performance. Therefore, we propose hypothesis 2 as follow:

Hypothesis 2: There is a three-way interaction of challenge stressors, leader-member exchange (LMX), and positive stress mindset (PSM) in predicting job performance. For employees with high LMX, the relationship between challenge stressors and job performance will be weaker under low PSM situation than under high PSM situation. For employees with low LMX, the relationship between challenge stressors and job performance will be weaker under low PSM situation than under high PSM situation.

\section{DATA AND METHODOLOGY}

\subsection{Sample and Procedure}

We designed a questionnaire to test the hypothetical model. In order to measure the individual's work stressors, leader-member exchange, stress mindset, and their job performance, we have targeted the employees of Taiwan's general organizations as research participants. The employees must belong to a work team with direct supervisors. Random sampling was conducted to organizations for different occupations, including trading company, restaurants, travel agency, bank, salesperson and staff of gas station and train station. We went to organization to conduct the measurement at the appointed time. Each participant received a letter of ethical information, a questionnaire and an anonymous return envelope.

Eventually, we got 530 employees from different occupations in Taiwan as our research sample. After uncompleted questionnaires were excluded, a final sample of 487 cases were used for data analyses, with $91.89 \%$ response rate. Demographics showed that $57.6 \%$ of participants were females, with an average age of 26.10 years and average work tenure of 4.94 years. Most were single $(85.2 \%)$ and educated to college level (76.3\%).

\subsection{Measure}

Challenge stressors. We measured challenge stressors using the 6-item scale of Cavanaugh et al. (2000). A sample item was "The amount of time I spend at work." The Cronbach's alpha coefficient was 0.81 .

Leader-member exchange. We assessed leader-member exchange using the 7-item scale of Graen and Uhl-Bien (1995). A sample item was "I understand that my supervisor is satisfied with my performance." The Cronbach's alpha coefficient was 0.89.

Positive stress mindset. We measured stress mindset using the stress mindset measure-general (SMM-G) 8-item scale of Crum et al. (2013), but we treated the original four of eight positive items as a positive stress mindset and the other four inverted items 
as a negative stress mindset. A sample item was "Experiencing stress facilitates my learning and growth." The Cronbach's alpha coefficient was 0.69 .

Job performance. The 5-item job performance scale developed by Viswesvaran, Ones, and Schmidt (1996) was used. A sample item was "My working quality is high." The Cronbach's alpha coefficient was 0.70 . All variables in this study followed responses ranging from 1 (strongly disagree) to 5 (strongly agree).

Control variable. We included the demography for gender, age, tenure, marriage and education as control variables. Additionally, challenge stressors and hindrance stressors are two relevant variables; thus, we included hindrance stressors as control variables to exclude its effect. We measured hindrance stressors using the 6-item scale of Cavanaugh et al. (2000). A sample item was "The lack of job security I have." The Cronbach's alpha coefficient was 0.73 .

\subsection{Common Method Bias Check}

Since the collection of research data is came from the same source, which has doubts about the common method bias in research design, we use the Harman's one-factor test to perform a post hoc remedy of common method bias. According to Podsakoff and Organ (1986) suggestion, we need to consider all variable's items (including challenge stressors, leader-member exchange, positive stress mindset and job performance) as one-factor, and to judge the variation of the first principle component in the case of unrotated. If the total variance explained by a single factor is greater than $50 \%$, and there is a problem with common method bias. After conducting Harman's one-factor test, the total variation explained by the first principle component in this study is $29 \%$. Besides, we further include the control variable (i.e. hindrance stressors) in Harman's one-factor test, the value is reduced to $24 \%$, which means that the problem of common method bias is not serious.

\subsection{Discriminant Validity}

We examined the discriminant validity of variable measures by performing confirmatory factor analysis. Since a limited sample size relative to many parameters estimated in the model is difficult to confirm (Floyd \& Widaman, 1995), we created parcels of items for the analysis (including two or three items for each variable except stress mindset). Each parcel was constrained to load onto the latent construct without any error covariance. First, we treated all variables as one-factor model (chi-square $=905.614$, $d f=90 ; \mathrm{CFI}=0.551 ; \mathrm{NNFI}=0.477 ; \mathrm{RMSEA}=0.136 ; \mathrm{SRMR}=0.117$ ). Second, we treated challenge and hindrance stressors as one factor, and the other three variables as another factor, built two-factor model (chi-square $=708.164, d f=89 ; \mathrm{CFI}=0.660 ; \mathrm{NNFI}=$ 0.598; RMSEA = 0.120; SRMR = 0.117). Third, we drew out dependent variable (job performance) as a single factor, which formed three-factor model (chi-square $=513.023, d f=87 ; \mathrm{CFI}=0.766$; NNFI = 0.717; RMSEA =0.100; SRMR =0.097). Then, we separated two moderators as different factors, resulted in four-factor model (chi-square $=382.515, d f=84 ; \mathrm{CFI}=0.836 ; \mathrm{NNFI}=0.795 ; \mathrm{RMSEA}$ $=0.085$; SRMR $=0.084$ ). Finally, we divided all variables and built five-factor model, the result indicated that the five-factor model (chi-square $=217.232, d f=80 ; \mathrm{CFI}=0.925 ; \mathrm{NNFI}=0.901 ; \mathrm{RMSEA}=0.059 ; \mathrm{SRMR}=0.057$ ) fits the data better than the other four models. These results illustrate that the discriminant validity of each variable was existence.

\section{FINDINGS}

The research framework is a three-way interaction model, we expected that positive stress mindset would have an additional moderating effect beyond the interaction effect of challenge stressor and LMX on job performance. We conducted a hierarchical regression analysis by using SPSS Statistics 22 to test whether the three-way interaction effect exists.

Table 1 showed all variables' mean, standard deviation, correlation coefficient, and reliability. As you can see, challenge stressor was positively correlated with $\operatorname{LMX}(r=0.29, p<0.001)$, PSM $(r=0.026, p<0.001)$ and job performance $(r=0.56, p<0.001)$. These results show initial support for our research hypotheses. The hierarchical regression results were showed in table 2 . In model 1 , we put in control variables to exclude their effects. Then, we put challenge stressors in model 2 , challenge stressors were positive and significantly predicted job performance $(\beta=0.550, p<0.001)$, so our hypothesis 1 was supported. Besides, model 3 also showed that challenge stressors were positively predicted $\operatorname{LMX}(\beta=0.209, p<0.001)$ and $\operatorname{PSM}(\beta=0.183, p<0.001)$. We further consider three two-way interaction terms to predict job performance in model 4 , and there is only the interaction term of challenge stressors and $L M X$ has a significant negative moderated effect on job performance $(\beta=-0.122, p<0.01)$. Finally, we put the three-way interaction term to predict job performance in model 5 , the results revealed that there is a positive effect $(\beta=$ $0.159, p<0.01$ ) on job performance, these findings primary support our hypothesis 2. 
Table 1: Correlation Table

\begin{tabular}{|c|c|c|c|c|c|c|c|c|c|c|c|c|}
\hline Variables & Means & $S D$ & 1 & 2 & 3 & 4 & 5 & 6 & 7 & 8 & 9 & 10 \\
\hline 1.Gender & 1.57 & .50 & - & & & & & & & & & \\
\hline 2.Age & 26.10 & 10.71 & .04 & - & & & & & & & & \\
\hline 3.Tenure & 4.94 & 7.92 & .06 & $.88^{* * *}$ & - & & & & & & & \\
\hline 4.Marriage & 1.14 & .35 & .06 & $.81^{* * *}$ & $.75^{* * *}$ & - & & & & & & \\
\hline 5.Education & 2.84 & .53 & .09 & .01 & $-.09^{*}$ & -.09 & - & & & & & \\
\hline 6.HS & 2.72 & .69 & .00 & .05 & .03 & .06 & .02 & $(.81)$ & & & & \\
\hline 7.CS & 3.60 & .63 & .02 & $.21^{* * *}$ & $.16^{* * *}$ & $.16^{* * *}$ & $.14^{* *}$ & $.22^{* * *}$ & $(.73)$ & & & \\
\hline 8.LMX & 3.36 & .63 & $-.13^{* *}$ & -.00 & -.04 & -.02 & .04 & -.07 & $.29^{* * *}$ & $(.89)$ & & \\
\hline 9.PSM & 3.62 & .56 & -.04 & -.09 & $-.09^{*}$ & $-.11^{*}$ & .05 & .01 & $.26^{* * *}$ & $.39^{* * *}$ & (.69) & \\
\hline 10.JP & 3.57 & .54 & -.01 & $.15^{* *}$ & $.13^{* *}$ & $.09^{*}$ & $.11^{*}$ & $.11^{*}$ & $.56^{* * *}$ & $.38^{* * *}$ & $.39^{* * *}$ & (.70) \\
\hline
\end{tabular}

Note: $\mathrm{N}=487$. Reliabilities are reported in parentheses. $\mathrm{HS}=$ hindrance stressor; $\mathrm{CS}=$ challenge stressor; $\mathrm{LMX}=$ leader-member exchange; PSM = positive stress mindset; JP = job performance.

Table 2: Three-way Moderation Regression Analyses on Job Performance

\begin{tabular}{|c|c|c|c|c|c|}
\hline & \multirow{2}{*}{\multicolumn{5}{|c|}{ Job Performance }} \\
\hline & & & & & \\
\hline & Model 1 & Model 2 & Model 3 & Model 4 & Model 5 \\
\hline \multicolumn{6}{|l|}{ Control Variable } \\
\hline Gender & -.026 & -.029 & .002 & -.001 & -.004 \\
\hline Age & .146 & .009 & .008 & .007 & .023 \\
\hline Tenure & .068 & .092 & .118 & .133 & .125 \\
\hline Marriage & -.074 & -.067 & -.044 & -.061 & -.069 \\
\hline Education & $.111^{*}$ & .043 & .042 & .042 & .037 \\
\hline Hindrance Stressor & $.103^{*}$ & -.012 & .024 & .011 & -.004 \\
\hline \multicolumn{6}{|l|}{ Independent Variable } \\
\hline Challenge Stressors (CS) & & $.550^{* * *}$ & $.427^{* * *}$ & $.417^{* * *}$ & $.399^{* * *}$ \\
\hline \multicolumn{6}{|l|}{ Moderator } \\
\hline Leader-Member Exchange (LMX) & & & $.209^{* * *}$ & $.184^{* * *}$ & $.147^{* * *}$ \\
\hline Positive Stress Mindset (PSM) & & & $.183^{* * *}$ & $.204^{* * *}$ & $.179^{* * *}$ \\
\hline \multicolumn{6}{|l|}{ Two-Way Interaction } \\
\hline $\mathrm{CS} \times \mathrm{LMX}$ & & & & $-.122^{* *}$ & $-.095^{*}$ \\
\hline $\mathrm{CS} \times \mathrm{PSM}$ & & & & .051 & $.116^{*}$ \\
\hline $\mathrm{LMX} \times \mathrm{PSM}$ & & & & -.061 & -.051 \\
\hline \multicolumn{6}{|l|}{ Three-Way Interaction } \\
\hline $\mathrm{CS} \times \mathrm{LMX} \times \mathrm{PSM}$ & & & & & $.159^{* *}$ \\
\hline$R^{2}$ & & .049 & .318 & .409 & .426 \\
\hline $\mathrm{F}$ & & $4.087^{* *}$ & $31.968^{* * *}$ & $36.750^{* * *}$ & $29.290^{* * *}$ \\
\hline$\Delta \mathrm{R}^{2}$ & & & .270 & .091 & .016 \\
\hline$\Delta \mathrm{F}$ & & & $189.620^{* * *}$ & $36.774^{* * *}$ & $4.489^{* *}$ \\
\hline
\end{tabular}

To determine the form of the interaction, we following the approach recommended by Aiken and West (1991), the pattern of the three-way interaction between challenge stressors, LMX and PSM on job performance is illustrated in figure 1. Also, we further examined whether pairs of slopes differed significantly at high and low levels (above and below 1 SD) of LMX and PSM by using the slope difference test, and the results are shown in table 3 . The results of simple slopes analysis indicate that, for employees 
with high LMX, the relationship between challenge stressors and job performance was weaker when PSM is low $(\beta=0.175, p<$ $0.01)$ than PSM is high $(\beta=0.388, p<0.001)$, and the slope difference test shows there is a significant difference between high LMX with high PSM situation and high LMX with low PSM situation (table $3 ; t=2.782, p<0.01$ ). On the other hand, for employees with low LMX, the relationship between challenge stressors and job performance was weaker under low PSM situation ( $\beta=0.379$, $p<0.001$ ) than high PSM situation $(\beta=0.431, p<0.001)$, although there is no significant difference between low LMX with high PSM situation and low LMX with low PSM situation (table 3; $t=0.998, n s)$. These findings support our hypothesis 2.

Figure 1: Three-way Interaction Effects of Challenge Stressors (CS), Leader-Member Exchange (LMX), and Positive Stress Mindset (PSM) on Job Performance

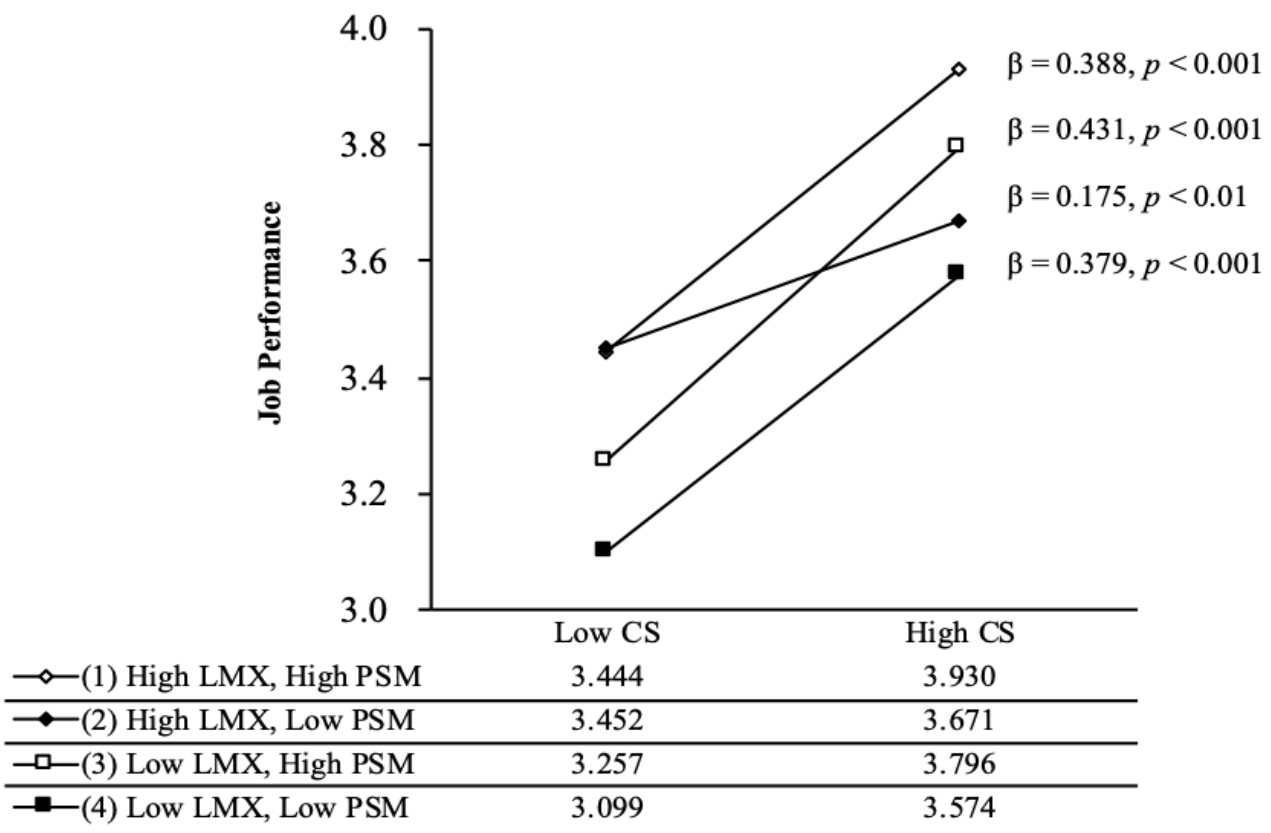

Table 3: Results of Slope Difference Tests

\begin{tabular}{lcc}
\hline Pair of Slopes & t-value & p-value \\
\hline (1) High LMX high PSM and (2) High LMX low PSM & 2.782 & 0.006 \\
(1) High LMX high PSM and (3) Low LMX high PSM & -0.710 & 0.478 \\
(1) High LMX high PSM and (4) Low LMX low PSM & 0.134 & 0.893 \\
(2) High LMX low PSM and (3) Low LMX high PSM & -2.588 & 0.010 \\
(2) High LMX low PSM and (4) Low LMX low PSM & -3.365 & 0.001 \\
(3) Low LMX high PSM and (4) Low LMX low PSM & 0.998 & 0.319 \\
\hline
\end{tabular}

Note. LMX = leader-member exchange; PSM = positive stress mindset

Note: LMX = leader-member exchange; PSM = positive stress mindset.

\section{DISCUSSIONS}

First, our statistical results supported our hypotheses that challenge stressors were positively predicted job performance, and there was a three-way interaction moderation effect of challenge stressors, LMX and PSM on job performance. A contribution of the present study to research is that we linked job demands-resources model and stress mindset theory to explain a boundary condition effect in stress issue. Second, the interaction of high-quality of LMX and person characteristic of positive thinking of stressor play an incremental effect. However, it is worthy to mention, based on slope difference test shows in table 3, for high LMX with low PSM situation, the simple slope is significantly lower than the other three situations $(t=2.782, p<0.01 ; t=-2.588$, 
$p<0.05 ; \mathrm{t}=-3.365, p<0.01)$. These results may imply two things: one is that employees have good relationship with their leader but without positive stress mindset in mind, could not promote the relationship between challenge stressor and job performance. The other one is that the effect of PSM may better and larger than the effect of LMX on the relationship between challenge stressor and job performance. Specifically, for employees with high PSM, the relationship between challenge stressors and job performance was stronger when $\operatorname{LMX}$ is low $(\beta=0.431, p<0.001)$ than $\operatorname{LMX}$ is high $(\beta=0.388, p<0.001)$; and for employees with low PSM, the relationship between challenge stressors and job performance was stronger under low LMX situation ( $\beta=0.379, p$ $<0.001$ ) than high LMX situation $(\beta=0.175, p<0.01)$. We propose that these might have a substitutes effect of leadership (Kerr \& Jermier, 1978), such that followers are aware that they possess enough skills and knowledge to successfully accomplish task and act as a substitute for a supervisor's leadership behavior.

\subsection{Theoretical Implication}

First, according to job demands-resources model (Bakker \& Demerouti, 2017), job resources can refill employee energy which lost from job demands. Previous studies have emphasized that LMX has a social support role affecting the relationship between job demands and job performance (Loi, Ngo, Zhang, \& Lau, 2011). Although, our study has further considered boundary condition of LMX, and found that larger supplemental effect of LMX occur when employee has PSM toward job demands. Second, we agree with Crum et al. (2013) and argue that different stress mindsets can result in different behaviors. However, we improve the methodological way they employed that treated stress mindset as a spectrum based on the degree of stress-is-enhancing or stress-is-debilitating. We divided stress mindset scale into positive and negative factors which provide future researchers with an alternative research option.

\subsection{Empirical Implication}

We propose practical implications for organizations and managers based on results showed that the interaction of challenge stressor, leader-member exchange and positive stress mindset can enhance job performance. For organization, work tasks can be designed to be more challenging and creating a work atmosphere that overcomes challenges, provide employees with a challenge stressor for growth opportunities, such as setting deadlines for task completion and increasing job responsibilities and task complexity. At the same time, cultivating employees' positive thinking skills through education and training will help improve work performance. For managers, leaders should conduct suitable relationships with employees, sometimes too much helping social support may have potentially harmful effects (Beehr, Bowling, \& Bennett, 2010). We suggest that leaders should keep a favorable relationship quality with employee and assist employees to establish positive mindsets or develop their positive thinking by organizing learning activities or establishing psychological counseling units to help employees rethink the stressors they encountered. In addition, leaders can use LMX to play the role of social support, which will help employees connect their positive mindset to better adapt to the challenge stressors, and thus improve job performance.

\subsection{Limitations and Suggestion for Future Research}

Our study still has some limitations, and we also provide some suggestions for future research based on limitations. First limitation, we collected data from employee self-reporting source, it leads to common method variance concerns, data may have an inflation effect especially for job performance. Although we conducted Harman's one-factor test, and result shows that the variation of first principle component is lower than 0.5 , means there is no common method variance concerns. However, we still suggest future researchers should use supervisor-employee dyadic questionnaires to avoid common source's concerns. And our data only be collected once, there is no data at two different time points for non-response bias test. Future researchers should collect data in different time periods to avoid the problem of common methods bias. Second, we divided stress mindset scale into two factors without a pilot study to ensure the reliability, we recommend that follow-up studies should categorize more rigorously. Stress mindset is an individual psychological state after evaluating stressor, some studies have argued that the classification of stressors should vary from different individuals (González-Morales \& Neves, 2015). We suggest that future researchers can start with an appraisal perspective and consider more contextual factors. Third, this study only investigated challenge stressors and included hindrance stressors as the control variable, future research could treat hindrance stressors as the research variable to complete the framework. Besides, the future researcher may think about a different source of stress not only in the work task itself, but the stressor comes from organization, leaders, colleges, customers or family, and examine whether the stress mindset play moderating effect. Finally, our sample included only Taiwanese employees, so the results may be insufficient to generalize to other situations. We suggest that future research should increase sample size and use different scales and different occupational samples (such as public sector employees) to validate the results of this study. 


\section{CONCLUSION}

This study presented a three-way interaction framework based on the job demands-resources model, which is the additional moderated effect of positive stress mindset behind the interaction effect of challenge stressors and leader-member exchange and on job performance. This give advises for practitioner and managers, not only design challenging work task and encouraging the employee to keep positive thinking mindset, but also maintain a favorable relationship quality for leader and subordinates, these can improve job performance for organizations.

\section{REFERENCES}

Abbas, M., \& Raja, U. (2019). Challenge-hindrance stressors and job outcomes: The moderating role of conscientiousness. Journal of Business and Psychology, 34(2), 189-201.

Aiken, L. S., \& West, S. G. (1991). Multiple regression: Testing and interpreting interactions. Thousand Oaks, CA, US: Sage Publications, Inc. Atkinson, W. (2004). Stress: Risk management's most serious challenge? Risk Management, 51(6), 20-26.

Bakker, A. B., \& Demerouti, E. (2007). The job demands-resources model: State of the art. Journal of Managerial Psychology, 22(3), 309-328. doi:10.1108/02683940710733115

Bakker, A. B., \& Demerouti, E. (2017). Job demands-resources theory: Taking stock and looking forward. Journal of Occupational Health Psychology, 22(3), 273.

Bakker, A. B., Demerouti, E., de Boer, E., \& Schaufeli, W. B. (2003). Job demands and job resources as predictors of absence duration and frequency. Journal of Vocational Behavior, 62(2), 341-356. doi:https://doi.org/10.1016/S0001-8791(02)00030-1

Bakker, A. B., Demerouti, E., \& Sanz-Vergel, A. I. (2014). Burnout and Work Engagement: The JD-R Approach. Annual Review of Organizational Psychology and Organizational Behavior, 1(1), 389-411. doi:10.1146/annurev-orgpsych-031413-091235

Beehr, T. A., Bowling, N. A., \& Bennett, M. M. (2010). Occupational stress and failures of social support: When helping hurts. Journal of Occupational Health Psychology, 15(1), 45-59.

Bliese, P. D., Edwards, J. R., \& Sonnentag, S. (2017). Stress and well-being at work: A century of empirical trends reflecting theoretical and societal influences. Journal of Applied Psychology, 102(3), 389.

Bodenmann, G., Meuwly, N., Bradbury, T. N., Gmelch, S., \& Ledermann, T. (2010). Stress, anger, and verbal aggression in intimate relationships: Moderating effects of individual and dyadic coping. Journal of Social and Personal Relationships, 27(3), 408-424.

Campbell, N. S., Perry, S. J., Maertz Jr, C. P., Allen, D. G., \& Griffeth, R. W. (2013). All you need is... resources: The effects of justice and support on burnout and turnover. Human Relations, 66(6), 759-782.

Cavanaugh, M. A., Boswell, W. R., Roehling, M. V., \& Boudreau, J. W. (2000). An empirical examination of self-reported work stress among U.S. managers. Journal of Applied Psychology, 85(1), 65-74. doi:10.1037//0021-9010.85.1.65

Cooper, C. L., Dewe, P., \& O'Driscoll, M. P. (2001). Organizational stress: A review and critique of theory, research and applications: SAGE Publications, Inc.

Crum, A. J., Salovey, P., \& Achor, S. (2013). Rethinking stress: The role of mindsets in determining the stress response. Journal of Personality and Social Psychology, 104(4), 716-733. doi:10.1037/a0031201

Demerouti, E., Bakker, A. B., Nachreiner, F., \& Schaufeli, W. B. (2001). The job demands-resources model of burnout. Journal of Applied Psychology, 86(3), 499-512. doi:10.1037/0021-9010.86.3.499

Dunegan, K. J., Duchon, D., \& Uhl-Bien, M. (1992). Examining the Link Between Leader Member Exchange and Subordinate Performance: The Role of Task Analyzability and Variety as Moderators. Journal of Management, 18(1), 59-76. doi:10.1177/014920639201800105

Dweck, C. S. (2008). Can personality be changed? The role of beliefs in personality and change. Current Directions in Psychological Science, 17(6), 391-394. doi:10.1111/j.1467-8721.2008.00612.x

Floyd, F. J., \& Widaman, K. F. (1995). Factor analysis in the development and refinement of clinical assessment instruments. Psychological Assessment, 7(3), 286-299.

$\mathrm{Fu}, \mathrm{N}$. (2013). Exploring the impact of high performance work systems in professional service firms: A practices-resources-uses-performance approach. Consulting Psychology Journal: Practice and Research, 65(3), 240-257. doi:10.1037/a0034502 
Ganster, D. C., \& Rosen, C. C. (2013). Work stress and employee health: A multidisciplinary review. Journal of Management, 39(5), 1085-1122.

González-Morales, M. G., \& Neves, P. (2015). When stressors make you work: Mechanisms linking challenge stressors to performance. Work \& Stress, 29(3), 213-229. doi:10.1080/02678373.2015.1074628

Graen, G. B. (1976). Role making processes within complex organizations. In M. D. Dunnette (Ed.), Handbook of Industrial and Organizational Psychology (pp. 1201-1245). Chicago: Rand McNally.

Graen, G. B., \& Scandura, T. A. (1987). Toward a psychology of dyadic organizing. In B. M. Staw \& L. L. Cummings (Eds.), Research in organizational behavior vol.9 (pp. 175-208). Greenwich, CT: JAI Press.

Graen, G. B., \& Uhl-Bien, M. (1995). Relationship-based approach to leadership: Development of leader-member exchange (LMX) theory of leadership over 25 years: Applying a multi-level multi-domain perspective. The Leadership Quarterly, 6(2), 219-247. doi:10.1016/10489843(95)90036-5

Grandey, A. A., Dickter, D. N., \& Sin, H.-P. (2004). The customer is not always right: customer aggression and emotion regulation of service employees. Journal of Organizational Behavior, 25(3), 397-418. doi:10.1002/job.252

Karatepe, O. M., Yavas, U., \& Babakus, E. (2007). The Effects of Customer Orientation and Job Resources on Frontline Employees' Job Outcomes. Services Marketing Quarterly, 29(1), 61-79. doi:10.1300/J396v29n01_04

Kerr, S., \& Jermier, J. M. (1978). Substitutes for leadership: Their meaning and measurement. Organizational Behavior and Human Performance, 22(3), 375-403.

Kurtessis, J. N., Eisenberger, R., Ford, M. T., Buffardi, L. C., Stewart, K. A., \& Adis, C. S. (2017). Perceived organizational support: A meta-analytic evaluation of organizational support theory. Journal of Management, 43(6), 1854-1884.

Lazarus, R. S., \& Folkman, S. (1984). Stress, appraisal, and coping. New York: Springer Publishing Company.

LePine, J. A., Podsakoff, N. P., \& LePine, M. A. (2005). A meta-analytic test of the challenge stressor-hindrance stressor framework: An explanation for inconsistent relationships among stressors and performance. Academy of Management Journal, 48(5), 764-775. doi:10.5465/amj.2005.18803921

Liden, R. C., \& Maslyn, J. M. (1998). Multidimensionafity of Leader-Member Exchange: An Empirical Assessment through Scale Development. Journal of Management, 24(1), 43-72. doi:10.1177/014920639802400105

Liden, R. C., Sparrowe, R. T., \& Wayne, S. J. (1997). Leader-member exchange theory: The past and potential for the future. In G. R. Ferris (Ed.), Research in personnel and human resources management, Vol. 15. (pp. 47-119). US: JAI Press.

Lin, W., Ma, J., Wang, L., \& Wang, M. (2015). A double-edged sword: The moderating role of conscientiousness in the relationships between work stressors, psychological strain, and job performance. Journal of Organizational Behavior, 36(1), 94-111.

Loi, R., Ngo, H. Y., Zhang, L., \& Lau, V. P. (2011). The interaction between leader-member exchange and perceived job security in predicting employee altruism and work performance. Journal of Occupational and Organizational Psychology, 84(4), 669-685.

McEwen, B. S., \& Seeman, T. (1999). Protective and damaging effects of mediators of stress: Elaborating and testing the concepts of allostasis and allostatic load. Annals of the New York Academy of Sciences, 896(1), 30-47. doi:10.1111/j.1749-6632.1999.tb08103.x

Medler-Liraz, H. (2014). Negative affectivity and tipping: The moderating role of emotional labor strategies and leader-member exchange. International Journal of Hospitality Management, 36, 63-72. doi:10.1016/j.ijhm.2013.08.010

Podsakoff, N. P., LePine, J. A., \& LePine, M. A. (2007). Differential challenge stressor-hindrance stressor relationships with job attitudes, turnover intentions, turnover, and withdrawal behavior: A meta-analysis. Journal of Applied Psychology, 92(2), 438-454. doi:10.1037/0021-9010.92.2.438

Podsakoff, P. M., \& Organ, D. W. (1986). Self-reports in organizational research: Problems and prospects. Journal of Management, 12(4), 531-544.

Rafferty, A. E., \& Griffin, M. A. (2006). Perceptions of organizational change: A stress and coping perspective. Journal of Applied Psychology, 91(5), 1154-1162. doi:10.1037/0021-9010.91.5.1154

Schwabe, L., \& Wolf, O. T. (2010). Learning under stress impairs memory formation. Neurobiol Learn Mem, 93(2), 183-188. doi:10.1016/j.nlm.2009.09.009

Thomas, C. H., \& Lankau, M. J. (2009). Preventing burnout: The effects of LMX and mentoring on socialization, role stress, and burnout. Human Resource Management, 48(3), 417-432.

Viswesvaran, C., Ones, D. S., \& Schmidt, F. L. (1996). Comparative analysis of the reliability of job performance ratings. Journal of Applied Psychology, 81(5), 557-574. 
Wallace, J. C., Edwards, B. D., Arnold, T., Frazier, M. L., \& Finch, D. M. (2009). Work stressors, role-based performance, and the moderating influence of organizational support. Journal of Applied Psychology, 94(1), 254-262. doi:10.1037/a0013090

Wayne, S. J., Shore, L. M., \& Liden, R. C. (1997). Perceived organizational support and leader-member exchange: A social exchange perspective. Academy of Management Journal, 40(1), 82-111.

Webster, J. R., Beehr, T. A., \& Christiansen, N. D. (2010). Toward a better understanding of the effects of hindrance and challenge stressors on work behavior. Journal of Vocational Behavior, 76(1), 68-77. doi:10.1016/j.jvb.2009.06.012 